\title{
Research on the Operation Mode of Practical Teaching in Application-Oriented Universities based on the Orientation of Innovation and Entrepreneurship Education
}

\author{
Zhang Huiqin*, Deng Xinyuan, Yang Tian \\ College of Economics and Management, Heilongjiang Bayi Agricultural University, Daqing, \\ 163319, Heilongjiang, China
}

\begin{abstract}
Keywords: Practice innovation; Innovation and entrepreneurship education; Professional service team

Abstract: practical teaching plays an important role in the study of professional knowledge in colleges and universities. Based on the actual situation and related characteristics of professional practice in application-oriented universities, this paper investigates and analyzes students' cognition and demand orientation of professional practice teaching, and then constructs a professional practice service team mode integrating project design - task driven - ability oriented - practice innovation. In this way, students' learning enthusiasm can be aroused, their innovation consciousness and teamwork consciousness can be cultivated, their practical ability can be improved, and their comprehensive quality can be expanded.
\end{abstract}

\section{Introduction}

Strengthening innovation and entrepreneurship education and training top innovation talents are important measures for universities to implement innovation-driven development strategy. The outline of the national program for medium - and long-term education reform and development (2010-2020) calls for innovation in the training model of talents and the combination of education and teaching with productive labor and social practice, especially in the field of higher education. Practice teaching plays a very important role in application-oriented university teaching, which is related to the quality and effect of university personnel training.

The thought and development of practice teaching in foreign universities have a long history. Germany is mainly enterprise oriented, France is centered on apprenticeship training, Canada is centered on curriculum development, and Australia implements competency based practical teaching models[1].American colleges and universities have created internship and internship models, teaching models centered on cases, problems and projects, as well as practical teaching 
models based on industry-university-research model, cooperative education model and community service model[2].Guanghua Z (2006) proposed to construct a multi-directional teaching system suitable for practical teaching[3]. In recent years, the innovation and entrepreneurship education has been put forward in practice teaching. The United States was the first country to carry out innovation and entrepreneurship education, from academic research in universities to the study of entrepreneur funds, to encourage students to carry out entrepreneurship practice, and started the first entrepreneurship education course in Harvard University. The UK also established the innovation and entrepreneurship center in 1999, proposing the practice of university students to carry out innovation education. Japan also applies the innovation of college students' practical teaching and university education, and carries out the education of entrepreneurial skills. Chinese scholars also put forward from the experience type teaching, for a particular course to strengthen students' management practical ability of administration[4], more and more in some higher vocational colleges, from the professional skills to practice ability, some scholars put forward the orientation in social situations and digital enterprise practice platform[5-6];Other scholars proposed practical models based on post orientation, vocational ability training and school-enterprise cooperation[7-9].Other scholars proposed the innovation and entrepreneurship education system and practical teaching orientation [10-12].

Based on the existing research findings, the cultivation of innovation and entrepreneurship ability of universities at home and abroad is mainly carried out by enterprises, schools and governments. This paper mainly focuses on the practical teaching mode and the improvement of innovation and entrepreneurship ability. Due to the different professional attributes, the practice teaching mode has not yet formed a systematic and comprehensive innovation mode that can adapt to the modern national innovation and entrepreneurship practice, and the guarantee of operation mechanism is still insufficient. Therefore, based on the innovation ability cultivation and promotion as the breakthrough point, through field investigation applied the running status of practice teaching in colleges and universities is analyzed innovation entrepreneurship education oriented professional practice teaching mode and operation mechanism, in order to improving the quality of practical link of practice teaching in colleges and universities to cultivate, to adapt to the global innovation entrepreneurship education thought idea, cultivate high-level innovative entrepreneurial talent.

\section{Applied Cognitive and Demand of the Practice Teaching of the College Professional Internship Survey}

\subsection{The Current Mode of Professional Practice}

The practical teaching system of practical practice in application-oriented universities generally includes cognitive practice, professional practice and graduation practice. Cognitive practice usually takes place in the first and second grades. Through visits and examinations, students can have a comprehensive understanding of the general process of production and operation and get ready for professional learning. Professional practice is usually in the third grade. After learning the courses of professional theory, I will go to the site of production and management for practical thinking and join them to consolidate the application of professional knowledge in practice. Graduation practice is generally the fourth grade, to comprehensive application of all professional knowledge. 


\subsection{Survey on Students' Cognition and Needs of Professional Practice}

In order to deeply understand the object of cognition and the demand of the practice teaching of the college of professional practice, this paper, taking a applied in colleges and universities in Heilongjiang province as an example, in June 2019 for the big three and senior grade of the same profession of administration of students for the professional practice effect and demand survey, most senior student has to find a job during the survey, some students are looking for.

The total sample was 161 people, among which 75 were investigated in junior year and 86 in senior year. It is found that students agree with the period and time of the current internship. More than $80 \%$ of students agree with the internship during the junior year, and 1-4 weeks is more appropriate.74\% of students believe that there is a close relationship between practical ability and employment, indicating that students have high expectations for professional internship, and the cognitive status of senior students is also such. For different internship methods, students prefer to practice in off-campus enterprises. Even if the simulated internship is conducted on campus, students' sense of identity is only $9.8 \%$, indicating that students are eager to contact with off-campus practical training. In addition, from the perspective of actual employment of senior students, $40 \%$ of students are employed in enterprises.

\subsection{Problems Existing in the Connection Between Practice Units and Students}

Through interviews with internship units and employers, it can be seen that the number of students that internship units can accommodate is limited, and sometimes internship work and professional docking is not very strong, students do not identify with the work of the major is not appropriate; The internship unit hopes that students can also complete some simple work tasks during the internship. However, due to the early training or previous guidance required to enter the internship position, the internship unit is often burdened with extra work, and it is difficult for students to integrate into it in a short period of time, so they can only do some simple work, resulting in the poor connection between the two sides.

\section{Design of Practical Service Team Building Scheme for Application Universities}

\subsection{Design Objectives and Ideas}

In order to better complete the professional knowledge and practice teaching effective connection, there is caused by the unequal of supply and demand on both sides to avoid residents of phenomenon, through the discussion with the internship units and student organization, is put forward when students participate together, off-campus internship as a case and project tasks, the school organization planning, the ability to determine the objectives and direction, set up relevant professional service team, and outside the enterprises to carry out docking, student teams design task execution scheme for implementation in the internship units, in the process, to mobilize students' learning, cultivate students' innovative consciousness and team cooperation consciousness, To improve students' practical ability and expand their comprehensive quality. 


\subsection{Operation Mode}

According to the basic principles of hierarchy, continuity and consistency of project design in project-based practical teaching mode, as well as the basic situation of professional knowledge teaching and students, the project practical design of professional service team is divided into three levels.

1) First-level project. This project is the basic practice layer, mainly applicable to the first-year students in the major. Mainly including the basic knowledge of the relevant knowledge development, with students as the theme, the teacher as the guidance; We can adopt the mode of the old leading the new so that the junior students can expand the knowledge of basic practice, expand the teamwork ability and improve the professional case analysis ability as the leaders. The project design at this level aims to cultivate students' ability of relevant professional basic knowledge and comprehensive practical basic ability, so as to lay a good foundation for subsequent project practice.

2) Secondary project. This project is a comprehensive innovation and practice layer, mainly applicable to sophomore students in the major. Projects at this level increase the content of autonomy and innovation, and can be designed and developed by the way that teachers set the students to choose the topic independently. At the same time, I can regularly organize relevant teams of my major who have participated in professional internships to share projects and exchange experiences.

3) Three-level projects. This project is the social practice layer, mainly including professional research, social practice and graduation project research. The purpose is to combine with the actual operation and management activities of enterprises, to promote students to actively participate in practice, active research and exploration, give full play to students' innovation potential, and shorten the employment adaptation period of students. At this stage we need from the school and the enterprise two aspects as consideration to design the internship programs and projects, to carry out the "internship project type", based on the enterprise actual production or research project, select, design difficulty suitable related corpus as internship programs, in real project as students practice content, take the enterprise project management mode, students in the form of the team, the integrated use of professional knowledge to complete the project.

\section{Implementation Guarantee and Process of Application-Oriented University Professional Practice Service Team}

In order to improve students' ability to analyze and solve practical problems, students' job adaptability and employment competitiveness. In the design and implementation of "enterprise project internship", it is necessary to ensure the perfection of various systems to effectively guarantee the implementation of the service team plan. The specific systems and processes are as follows.

1) The college actively communicates with enterprises in close cooperation with the internship. Based on the production or scientific research projects of the enterprise, the college and the enterprise jointly design internship projects, define the goals of internship projects and formulate internship project plans.

2) Enterprises release internship project topics; The students form their own teams to apply for the internship project, and conduct preliminary research on the application of internship project to form a preliminary project research plan. 
3) The college organizes professional teachers to select the team for applying internship projects; published internship project and was selected into the team; The project team participated in the enterprise internship.

4) Professional team managers regularly organize and hold project progress communication meetings, which are attended by corporate mentors and on-campus mentors. The internship project team reports project progress, proposes project difficulties and solutions, and makes work plans for the next stage.

\section{Conclusion}

Based on the applied university professional practice investigation and analysis of the current situation and existing problem, put forward to change practice outside the traditional focus on take lightly gives ideas, innovative to off-campus internship and project tasks as a case, through professional service team of the school organization planning, the ability to determine the objectives and guidance, and outside the enterprises to carry out docking, will the professional services team task of design scheme for practice in the internship units, in the hope of the organic combination of theory and practice, to cultivate college students' practice ability, cultivate their innovation consciousness and team consciousness, improve college students' comprehensive quality.

\section{Acknowledgment}

The paper was supported by Foundation Project: Heilongjiang Bayi Agricultural university reviewed, evaluated and rectified the university-level special project (Project Number: 2011020046).

\section{References}

[1]Richard Lovell Edgeworth, Practical $\quad$ Education. 2004 http://www.nal.vam.ac.uk/miniaturelibraries//practicaleduction.htm.

[2]Zhao Minggang (2011) Evaluation and analysis of practical teaching model in American universities. Education Review, 1, 156-158.

[3]Guanghua Z (2008) New Exploration on Practical Teaching Method for the Major of Marketing in Colleges. Educational Research, 2006(6): 86-89.

[4]He Zhongwei, Li Hua, Liu Fang. Experiential teaching and management practice of students. Xiaoxiao \& Occupation, 35, 116-117.

[5]Xie Jun. (2011) Design and value orientation of practical teaching innovation model in colleges and universities. Education Review, 4, 89-91.

[6]Duan Lihua, Liu Yi. (2016) Research and practice of innovation and entrepreneurship education system in vocational colleges based on "specialty +". Vocational Education Forum, 28, 23-27.

[7]Yan Ling, Huo Shuangshuang, Deng Jiaojiao. (2014) A study on the practical teaching of competency-based workshops -- a case study of engineering cost major in Tianjin university of technology. Modern Education Technology, 6, 113-121.

[8]Hu Xiaomin (2016) Design and construction of practical teaching system for economics and management. Laboratory Research and Exploration, 7, 276-280. 
[9]Wang Weifang, Jing Yongping (2018) Research on practical teaching problems and countermeasures under the positioning of high-quality applied talents -- a case study of undergraduate economics and management. Journal of National Institute of Education Administration, 3, 56-62.

[10]Gong Lixia (2011) Reflections on undergraduate education reform in application-oriented universities -discussion on the combination of innovation and entrepreneurship education and professional education. Journal of National Institute of Education Administration, 9, 14+45-48.

[11]Kong Lingshi (2017) Research on innovation and entrepreneurship education model of practice-oriented application-oriented undergraduate universities. Journal of Chifeng University (natural science edition), 20:154-155.

[12] Chu Zhaohui, Liu Peiping (2019) Research and practice of innovation and entrepreneurship education system in application-oriented universities. Journal of Chongqing University of Science And Technology (social science edition), 2, 96-99. 